\title{
Response to: Comment on "Intervention Effects of a School-Based Health Promotion Programme on Obesity Related Behavioural Outcomes"
}

\author{
Susanne Kobel, Tamara Wirt, Anja Schreiber, Dorothea Kesztyüs, Sarah Kettner, \\ Nanette Erkelenz, Olivia Wartha, and Jürgen M. Steinacker
}

Division of Sports and Rehabilitation, Department of Internal Medicine II, Ulm University Medical Centre, Frauensteige 6, Haus 58/33, 89075 Ulm, Germany

Correspondence should be addressed to Susanne Kobel; susanne.kobel@uni-ulm.de

Received 23 June 2015; Accepted 2 August 2015

Academic Editor: Bernhard H. Breier

Copyright (C) 2015 Susanne Kobel et al. This is an open access article distributed under the Creative Commons Attribution License, which permits unrestricted use, distribution, and reproduction in any medium, provided the original work is properly cited.

Evaluating multicomponent health programmes in public institutions is always a complex task and requires careful planning [1]. Reporting the outcomes in a precise and understandable manner is a further challenge for the researcher [2].

The points raised by $\mathrm{Li}$ et al. [3] are very valid and were also considered by us when writing the paper. Although outlined by Dreyhaupt et al. [4], not all planned analyses were incorporated in our paper [5]. Since the paper [5] (especially Methods) ended up being considerably substantial, we refrained from adding results of further statistical analyses to the paper. Further, in previous paper concerning crosssectional results of this study, we referred to the respective consideration of clustering effects including adequate statistical methods $[6,7]$. Since almost no clustering effects were observed, we refrained from introducing them in the present paper, even due to the associated complexity [2].

However, we have compared the results of the logistic regression models used and published in the paper with the results of generalised linear mixed models considering possible clustering effects in schools. Only a slight difference between odds ratios (ORs) was derived from the logistic regression models and the ORs from generalised linear mixed models for the variables "soft drink consumption" and "skipping breakfast." Hence, we refrained from explaining and mentioning it in the paper.

To reveal these above-mentioned slight differences between the results published in the paper and those derived
TABLE 1: Comparison of the results derived from logistic regression models and generalised linear mixed models.

\begin{tabular}{lccc}
\hline & $n$ & OR & 95\% CI \\
\hline $\begin{array}{l}\text { Physical activity, MVPA on } \geq 4 \\
\text { days/week } \geq 60 \text { minutes }\end{array}$ & 1386 & & \\
$\begin{array}{l}\text { Logistic regression model } \\
\text { Generalised linear mixed model }\end{array}$ & & 1.18 & {$[0.92,1.52]$} \\
$\begin{array}{l}\text { Screen media use, screen media } \\
\geq 1 \text { h/day }\end{array}$ & 1471 & & {$[0.92,1.52]$} \\
Logistic regression model & & 0.75 & {$[0.53,1.06]$} \\
$\begin{array}{l}\text { Generalised linear mixed model } \\
\text { Soft drink consumption, soft drinks }\end{array}$ & 1475 & & \\
$\geq 1$ time/week & & 0.75 & {$[0.53,1.06]$} \\
Logistic regression model & & 0.96 & {$[0.72,1.28]$} \\
Generalised linear mixed model & & 0.93 & {$[0.68,1.29]$} \\
$\begin{array}{l}\text { Breakfast habits, skipping breakfast } \\
\text { Logistic regression model }\end{array}$ & 1480 & & \\
Generalised linear mixed model & & 0.86 & {$[0.58,1.29]$} \\
\hline
\end{tabular}

OR: odds ratio; CI: confidence interval.

from mixed models accounting for clustering, we included Table 1, which shows the results from both types of analysis. The ORs for our outcome variables physical activity, screen media use, soft drink consumption, and breakfast habits 
show no significant differences, and therefore we assume no clustering effects in our data.

\section{Conflict of Interests}

The authors declare that there is no conflict of interests.

\section{References}

[1] P. Craig, P. Dieppe, S. Macintyre, S. Mitchie, I. Nazareth, and M. Petticrew, "Developing and evaluating complex interventions: the new Medical Research Council guidance," British Medical Journal, vol. 337, Article ID a1655, 2008.

[2] M. Casals, M. Girabent-Farrés, and J. L. Carrasco, "Methodological quality and reporting of generalized linear mixed models in clinical medicine (2000-2012): a systematic review," PLoS ONE, vol. 9, no. 11, Article ID 0112653, 2014.

[3] P. Li, A. W. Brown, J. M. Oakes, and D. B. Allison, "Comment on 'intervention effects of a school-based health promotion programme on obesity related behavioural outcomes"' Journal of Obesity, vol. 2015, Article ID 708181, 2 pages, 2015.

[4] J. Dreyhaupt, B. Koch, T. Wirt et al., "Evaluation of a health promotion program in children: study protocol and design of the cluster-randomized Baden-Württemberg primary school study [DRKS-ID: DRKS00000494]," BMC Public Health, vol. 12, no. 1, article 157, 2012.

[5] S. Kobel, T. Wirt, A. Schreiber et al., "Intervention effects of a school-based health promotion programme on obesity related behavioural outcomes," Journal of Obesity, vol. 2014, Article ID 476230, 8 pages, 2014.

[6] D. Kesztyüs, S. Kettner, S. Kobel et al., "Quality of life and frequency of sickness in school-children in correlation to activity and media consumption," Deutsche Zeitschrift fur Sportmedizin, vol. 64, no. 10, pp. 293-300, 2013.

[7] D. Kesztyüs, A. Schreiber, S. Kobel et al., "Illness and determinants of health-related quality of life in a cross-sectional sample of schoolchildren in different weight categories," GMS German Medical Science, vol. 12, no. 1, 2014. 


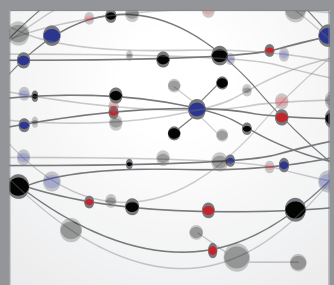

The Scientific World Journal
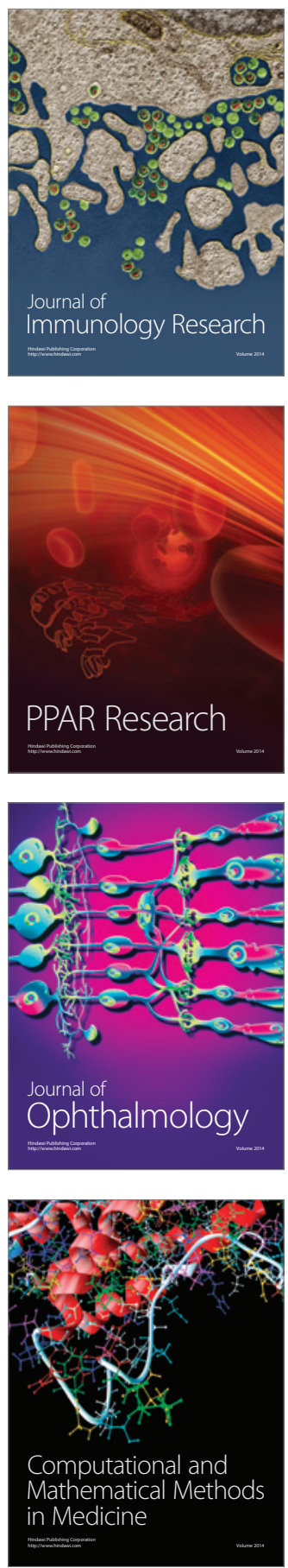

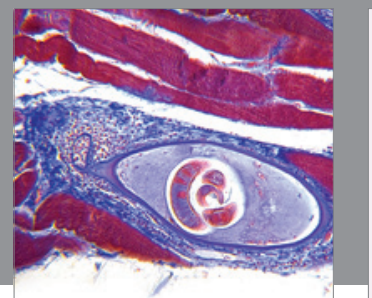

Gastroenterology

Research and Practice
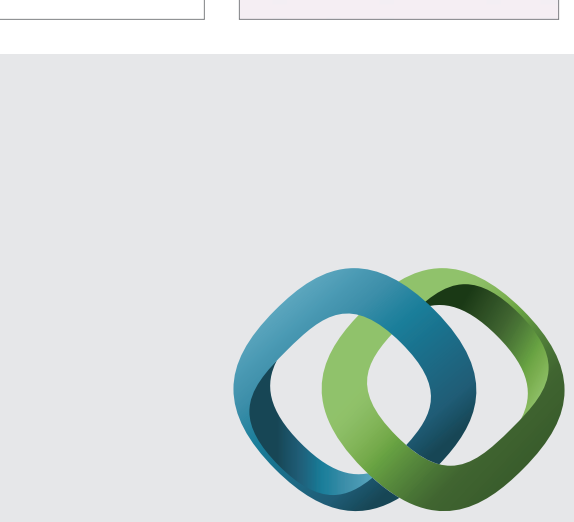

\section{Hindawi}

Submit your manuscripts at

http://www.hindawi.com
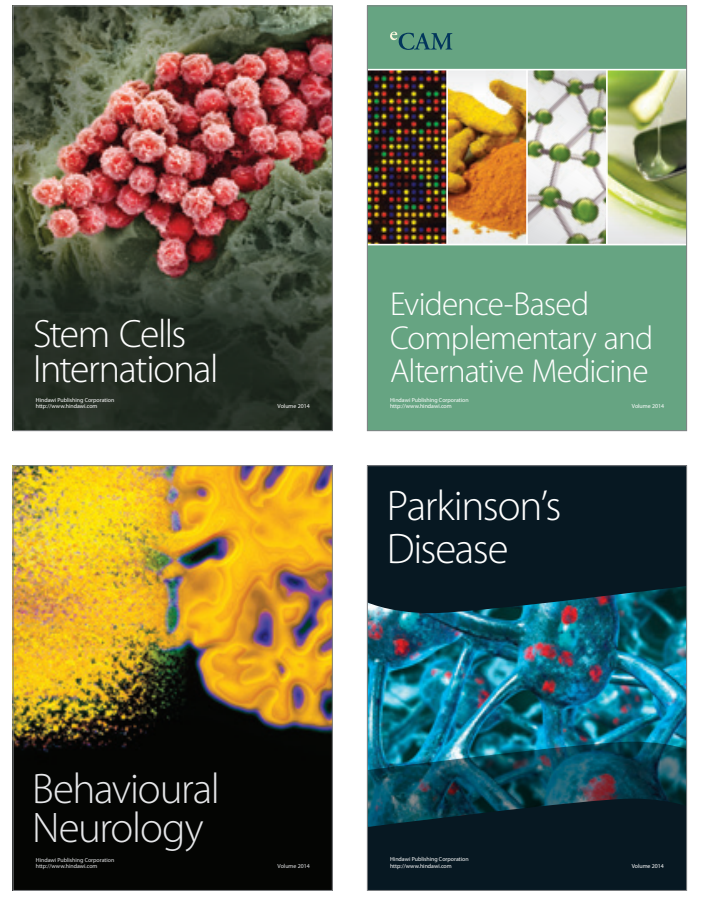
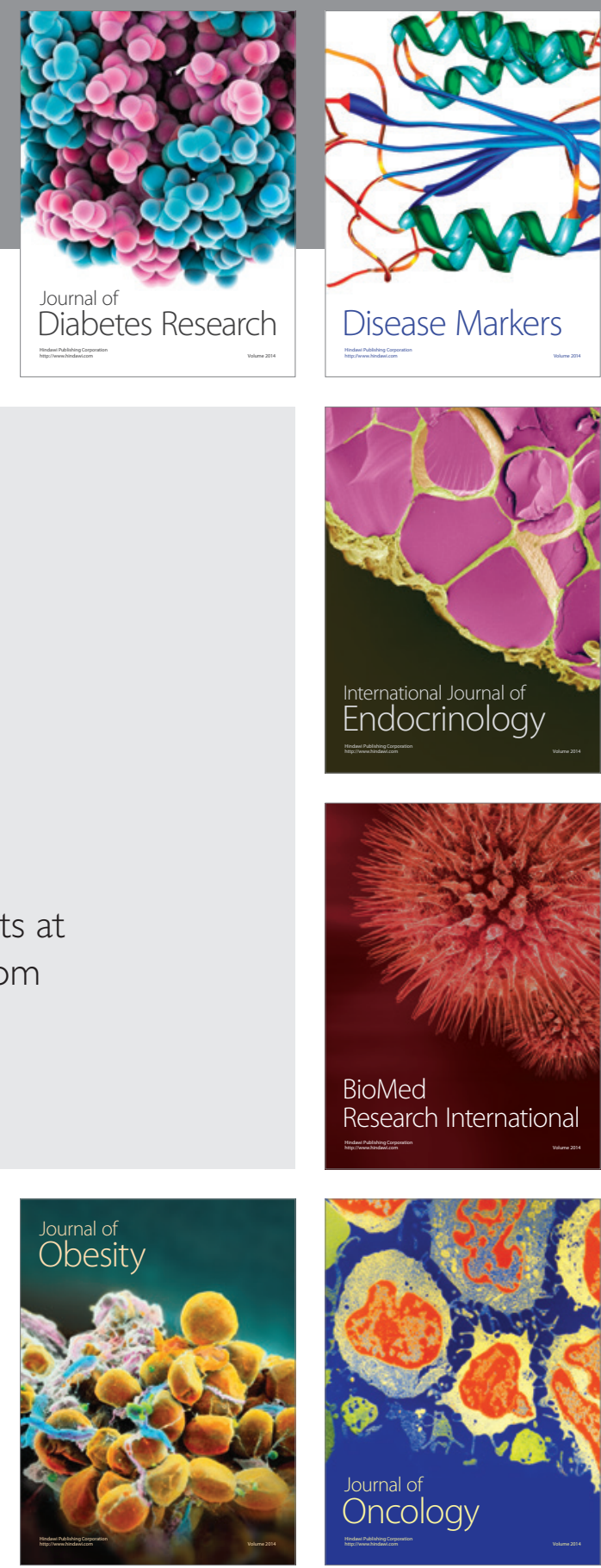

Disease Markers
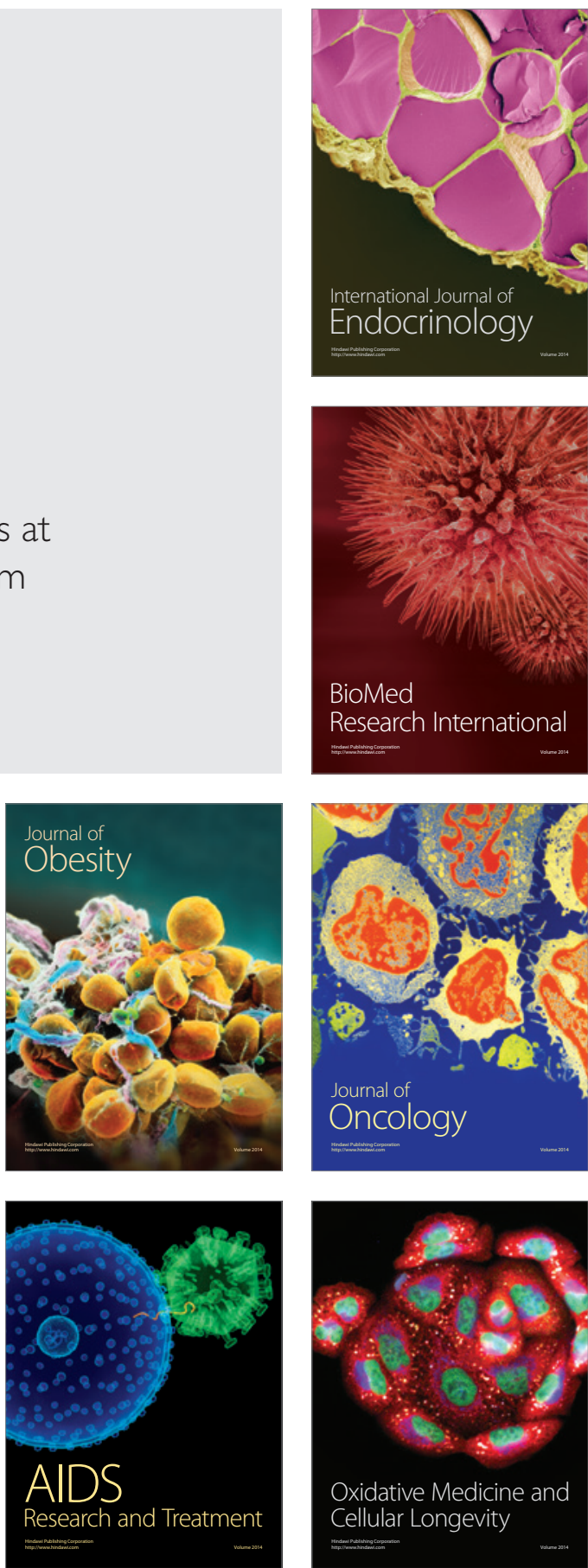